\title{
INDUCTION AND REDUCTION OF ANTI-HERBIVORE DEFENSES IN BROWN AND RED MACROALGAE OFF THE KENYAN COAST ${ }^{1}$
}

\author{
Janja Ceh ${ }^{2}$ \\ University of Vienna, Faculty of Life Sciences, Dr. Karl Lueger-Ring 1, 1010 Vienna, Austria \\ Markus Molis ${ }^{2,3}$ \\ Leibniz Institute of Marine Sciences, Düsternbrooker Weg 20, D-24105 Kiel, Germany
}

Thomas M. Dzeha

Department of Chemistry, Macquarie University, North Ryde, New South Wales 2109, Australia

and

Martin Wahl

Leibniz Institute of Marine Sciences, Düsternbrooker Weg 20, D-24105 Kiel, Germany

Herbivory is particularly intense in tropical benthic communities, suggesting preference of constitutive, rather than inducible, anti-herbivory defense. The objective of the study was to examine whether anti-herbivore defenses in the red alga Hypnea pannosa J. Agardh and the brown algae Sargassum asperifolium Hering and G. Martens ex J. Agardh and Cystoseira myrica (S.G. Gmelin) C. Agardh could be induced and subsequently reduced in response to grazing by the amphipod Cymadusa filosa Savigny. During a 14-day treatment phase, algae were exposed to amphipod grazing or were left ungrazed (control). Subsequently, one subset of algae was used in feeding assays, whereas another was cultivated for additional 14 days without consumers (recovery phase). At the end of each phase, bioassays were conducted to detect defensive traits in terms of differences in consumption rates of grazed and control pieces of live algae and agar-based food containing nonpolar algal extracts. Consumption of grazed live $S$. asperifolium and $H$. pannosa specimens was lower than of control algae. Furthermore, nonpolar extracts of grazed $S$. asperifolium and C. myrica were less preferred than those from control algae. Defensive responses were exclusively detected after the treatment phase, although strong preference of ungrazed $\mathrm{H}$. pannosa and $C$. myrica over grazed conspecifics continued throughout the recovery phase. These findings suggest that phenotypic plasticity in anti-herbivory defense of marine macroalgae 1) might be more

\footnotetext{
${ }^{1}$ Received 28 September 2004. Accepted 26 April 2005.

${ }^{2} \mathrm{~J}$. Ceh and M. Molis are equal authors.

${ }^{3}$ Author for correspondence and present address: Biological Station Helgoland, Foundation Alfred-Wegener-Institute for Polar and Marine Research, Kurpromenade 201, D-27498 Helgoland, Germany. e-mailmmolis@awi-bremerhaven.de.
}

common than previously shown, 2) could be switched on and off within 2 weeks, and 3) can be found in nonpolar algal extracts.

Key index words: alga-animal interaction; amphipods; Kenya; macroalgae; mesograzer

Abbreviation: DCM, dichloromethane

The distribution and abundance of seaweeds in both temperate and tropical communities are strongly affected by mesograzers (Brawley 1992) and macrograzers (Hay 1985). To persist in benthic communities, seaweeds must escape, tolerate, or deter herbivores (Lubchenco and Gaines 1981). In systems of intense herbivory (e.g. coral reefs; Hay 1997), palatable macroalgae are more susceptible to elimination if they are not defended against herbivory (Hay 1996, Cronin 2001). Therefore, it is not surprising that many tropical algal species produce anti-herbivore chemicals (Hay and Fenical 1988, Hay 1996).

Theoretical studies suggest that more plants display permanent rather than inducible defenses when herbivory is predictable (Adler and Karban 1994) or intense (Karban et al. 1999). On the other hand, constitutive chemical defense incurs several selective disadvantages, including 1) concurrence of grazer adaptations to defense (Agrawal and Karban 1999), 2) the risk of autotoxicity (Agrawal and Karban 1999), and 3) costs to produce and maintain defense (Karban 1993, Agrawal 1998, Baldwin 1998). In habitats with unpredictable herbivory, plants might optimize anti-herbivore defense, thus increasing their fitness, by inducing defenses rather than expressing them permanently (Harvell and Tollrian 1999). Consumption activities of mesograzers (e.g. amphipods) strongly reflect such variable grazing regimes, which are hypothesized to promote the evolution of phenotypic plastic defensive 
responses (Hay 1996). Furthermore, mesograzers often do not quickly kill their prey and can therefore be deterred by algal defense, which they themselves induced (Hay 1996).

Presently, no clear picture exists about how taxonomically widespread inducible defenses are in seaweeds. Possibly, inconsistent results from past studies on inducible defenses in seaweeds reflect the use of inappropriate setups. For instance, most former experiments used artificial wounding (clipping) instead of actual grazers to stimulate defensive responses (Hemmi et al. 2004) or changes in the phlorotannin concentration (Hammerström et al. 1998). Consequently, defenses could not be induced in clipping experiments where algae required grazer-associated cues. Furthermore, a strong emphasis in linking phlorotannin concentration with chemical defense in algae seems unjustified by present experimental evidence (Jormalainen et al. 2001, Deal et al. 2003, Kubanek et al. 2004), unless coupled with relevant bioassays.

The above might partly explain the striking discrepancy between the vast number of terrestrial studies and the few aquatic examples that document an inductive anti-herbivore response in plants. Because of the relatively low number of studied seaweeds, it is presently unclear whether this low number of inducible algae reflects an artifact of a biased research effort or an actual pattern. An induction of chemical herbivore repellents has been detected almost exclusively in brown seaweeds from temperate regions: Dictyota menstrualis (Cronin and Hay 1996), Ascophyllum nodosum (Pavia and Toth 2000), Sargassum filipendula (Sotka et al. 2002), Lobophora variegata (Weidner et al. 2004), and Fucus vesiculosus (Rohde et al. 2004). Recently, inducible anti-herbivore defenses have also been reported in the Brazilian red alga Pterocladiella capillacea (Weidner et al. 2004), suggesting that their occurrence is neither restricted to brown algae nor to temperate habitats. Moreover, it indicates the need to study the existence of inducible anti-herbivore defenses in seaweeds over a broader taxonomical and geographical range to assess how common the strategy of inducible defense is in seaweeds. In addition, past studies were confined to the onset of defenses. Nevertheless, it should be an integral and testable property of inducible anti-herbivore responses to reduce defenses after grazing has ceased. Yet experimental evidence on this process is extremely scant (Hemmi et al. 2004, Rohde et al. 2004, Weidner et al. 2004). Our study attempted to test experimentally 1) whether anti-herbivore defenses are induced after 14-day amphipod-grazing in two brown and one red Kenyan macroalgae, 2) whether induced defenses are reduced after grazing ceased for 14 days, and 3) whether induced defensive traits can be found in nonpolar algal extracts.

\section{MATERIALS AND METHODS}

Study site and organisms. Algae and herbivores were collected from the intertidal zone at Four Seasons Beach
(E $39^{\circ} 7^{\prime}, \mathrm{S} 4^{\circ} 1^{\prime}$ ), Mombassa, an algal-dominated rocky shore with relatively high nutrient levels (Uku and Björk 2001). The macroalgae used in this study were the brown algae Cystoseira myrica and Sargassum asperifolium and the red alga Hypnea pannosa. All three algal species and the algae-associated herbivorous amphipod Cymadusa filosa were conspicuously abundant at the study site during the time of sampling.

Experimental setup. The experiment was composed of a triphased induction experiment, assessing induction and reduction of anti-herbivore defenses in macroalgae. Preference feeding assays examined, on the basis of consumption rates, the relative difference in palatability levels between grazerexposed algae and ungrazed conspecifics.

For the induction experiment, 30 transparent plastic aquaria ( $2 \mathrm{~L}$ volume, $12 \times 18 \times 11 \mathrm{~cm}$ ) were continuously supplied with filtered $(100 \mu \mathrm{m}$ plankton mesh) natural seawater with a mean $( \pm$ SE) salinity of $34.80( \pm 0.24)$ at a mean temperature of $29.9( \pm 0.7)^{\circ} \mathrm{C}$. Water was pumped from the sea into the system twice a day at high tide into two plastic storage tanks (250 L volume each) placed above the aquaria. Using flow controllers, each aquarium was separately supplied with water from storage tanks at a flow rate of $20 \mathrm{~mL} \cdot \mathrm{min}^{-1}$. Two layers of white mosquito net $(1 \mathrm{~mm}$ mesh) were spanned above all containers to simulate mean ambient light levels of 1070.8 $( \pm 85.0) \mu \mathrm{mol}$ photons $\cdot \mathrm{m}^{-2} \cdot \mathrm{s}^{-1}$ (photoperiod, 12:12-h light:dark cycle) that were measured at the study site at a depth of $2 \mathrm{~m}$ during the study period.

Induction experiments. Experiments were conducted in an outdoor flow-through system at the Kenya Marine and Fisheries Research Institute in Mombassa, Kenya between April and June 2003. On 19 April 2003 five algal specimens per species were collected, cleaned of all visible epibionts, and rinsed several times with seawater. To reduce genotypic variation of anti-herbivore responses, eight similar-sized pieces were cut from a single specimen, weighed (wet mass $2.5-3 \mathrm{~g}$ ), and apportioned to a treatment and a control aquarium. Multiple thallus pieces per aquarium were necessary to perform multiple bioassays at different phases of the experiment. Induction experiments were divided into acclimation, treatment, and recovery phases, each lasting 14 days. During the acclimation phase, algal pieces were left without grazers in the aquaria to minimize defenses caused by possible grazing in the field (Duffy and Hay 1994, Hay, 1996). During the following treatment phase, the four algal pieces in the treatment aquaria were directly exposed to grazing by five amphipods, whereas the remaining four algal pieces served as ungrazed controls. Aquaria were checked twice a day, and dead herbivores were replaced by live conspecifics. After 2 weeks of grazing treatment, amphipods were removed, all aquaria cleaned, and the algae weighed. Two pieces of algae were taken out of each aquarium for the first series of choice preference feeding assays. One piece was immersed in dichloromethane (DCM), and extracts were used in agar-based feeding preference assays, whereas the second piece was directly used in an assay with amphipods. The remaining two pieces were left in the aquaria for recovery to detect whether putatively induced defenses decrease after a 14-day amphipod-free period. One of the recovering pieces was also used to measure autogenic changes in plant mass during the feeding assay. At the end of the recovery phase, the algae were weighed and used for the second set of preference feeding assays.

Preference feeding assays. Bioassays were conducted adjacently to the setup where the induction experiments were performed to assess grazing-mediated changes by $C$. filosa in palatability of live algae as well as artificial food. For both types of food, a single piece of a grazed alga and a control alga were offered simultaneously in transparent plastic containers ( $1 \mathrm{~L}$ volume, $20 \times 7 \times 7 \mathrm{~cm}$ ) to five amphipods in 
3-day choice preference feeding assays. Despite the container size, care was taken that abiotic conditions were identical between algae in the recovery phase and those used in feeding assays. To avoid adaptation effects, different amphipod individuals were used in the treatment phase of the induction experiment and in preference feeding assays. Before preference feeding assays, amphipods were cultivated in separate aquaria and fed on a diverse algal diet, because starvation may alter feeding preferences of some herbivores (Cronin and Hay 1996).

At the beginning and at the end of feeding assays, live algae were weighed with an analytical balance (Precisa $310 \mathrm{M}$, Precisa, Zurich, Switzerland) to the nearest milligram after spinning them five times in a salad spinner to remove excess seawater. To correct for changes in algal wet mass due to factors other than grazing (autogenic changes), we additionally weighed all algal individuals in the recovery phase at the beginning and end of preference feeding assays. The corrected amphipod consumption rate for a single piece of alga used in choice feeding assays was calculated as

$$
T_{\mathrm{i}}\left(C_{\mathrm{f}} / C_{\mathrm{i}}\right)-T_{\mathrm{f}}
$$

where $T_{\mathrm{i}}$ and $T_{\mathrm{f}}$ are the initial and final wet masses, respectively, of one algal piece subjected to grazing in a feeding assay and $C_{\mathrm{i}}$ and $C_{\mathrm{f}}$ are the initial and final masses, respectively, of growth control algae, that is, thallus pieces passing through the recovery phase. Autogenic changes in algae could not be assessed simultaneously for feeding assays performed after the recovery phase as would have been preferable, because our experimental design did not include an additional piece of each individual alga due to crowding in the containers. Thus, mass changes measured during the last 3 days of the recovery phase (i.e. the period matching closest the physiological state of the algae before the feeding assay) were used for the autogenic control value. During feeding assays, grazed and control algae were placed in the same container, thus being exposed to identical conditions, which could have affected autogenic changes in their wet mass. Consequently, any error resulting from our nonstandard autogenic controls is likely to be very small. The error, if any, probably should at most have had a small effect on the absolute levels and should not have influenced the relative differences in mass change between grazed and control pieces.

Food containing nonpolar extracts. Agar-based food was produced to reduce algal characteristics to their nonpolar compounds. Algae were dried in an oven at $30^{\circ} \mathrm{C}$ for 3 days, that is, mean ambient water temperature during the experiment, weighed, and shredded. Algae were dried to obtain a quantitative measurement, which allowed the adjustment of nutritious content and extracted compounds between live algae and artificial food made of powdered Ulva. Wet mass measurements of algae would have resulted in overestimating the required amount of Ulva powder (i.e. nutritious content) for preparing artificial food and consequently in a reduced relative quota of extracted compounds in artificial food items compared to original algae. Drying Ulva in an oven maximized comparability between drying events after treatment and recovery phases. Using DCM, the lipophilic compounds of both control and grazed algae were extracted $(1 \mathrm{~g}$ of alga wet mass $=1 \mathrm{~mL}$ DCM) for $1 \mathrm{~h}$. Extraction with DCM was repeated three times. The extract was mixed with $U$. lactuca powder (dry mass alga = mass $U$. lactuca powder) and, due to technical limitations, allowed to evaporate at room temperature on a laboratory bench for $24 \mathrm{~h}$. Ulva lactuca is known to be palatable for most herbivores and was previously used as a standard food base for algal extracts (Deal et al. 2003). After DCM was allowed to evaporate, $0.36 \mathrm{~g}$ agar was added to $10 \mathrm{~mL}$ distilled water, boiled, and allowed to cool for a minute before being mixed with the blend of extract and $U$. lactuca powder. The mixture was poured over a mosquito net (mesh size, $1 \mathrm{~mm}$ ) flattened between two glass plates, which were separated by $1 \mathrm{~mm}$. At the end of the preference feeding assays using artificial food, the number of all squares consumed was counted, where more than $50 \%$ of a square was consumed.

Statistical analysis. Using paired $t$-tests, differences in consumption rates of grazed and control algae were compared separately for each algal species, food type, and experimental phase. Homogeneity of variances was confirmed before the analysis with Levene's test and, where necessary, log-transformed to meet the assumptions.

\section{RESULTS}

Live algae as well as nonpolar algal extracts of control algae were generally preferred over grazed algal individuals (Fig. 1, A and B). In four of the six possible assay combinations (two types of feed for each of three algal species), relative feeding preference on control algae was lowered during the recovery phase. The brown alga Sargassum asperifolium showed the most consistent pattern of all tested algae.

Sargassum asperifolium. Live algae: At the end of the treatment phase, control algae were significantly

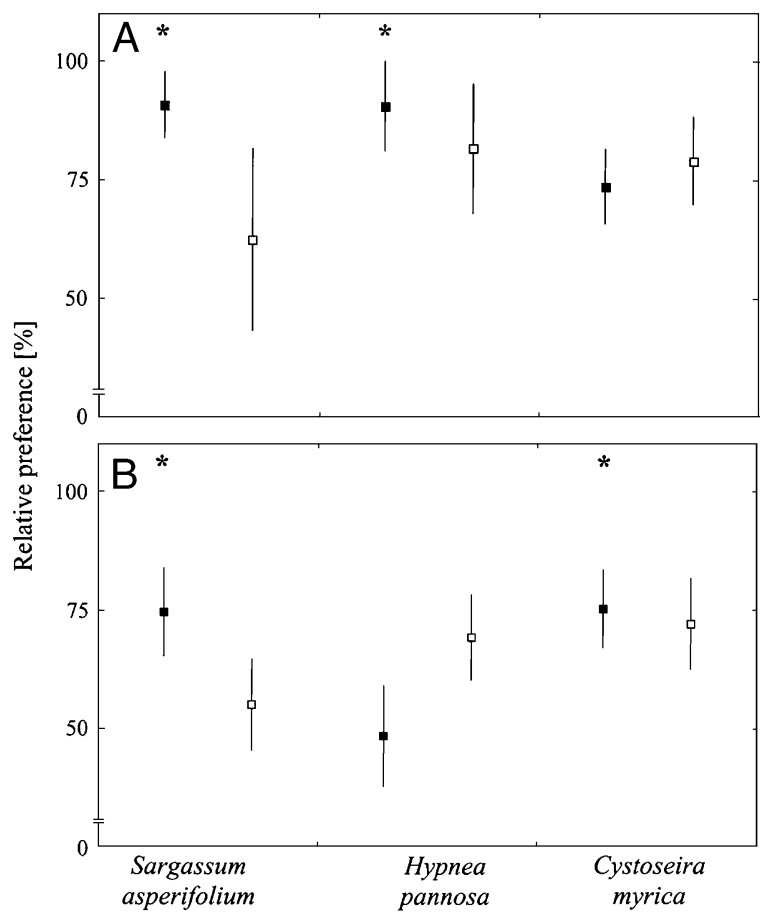

FIG. 1. Cymadusa filosa grazing on the red alga Hypnea pannosa and the brown algae Sargassum asperifolium and Cystoseira myrica. Graphs represent mean relative preference $( \pm \mathrm{SE})$ during 3-day choice feeding assays $(n=5)$ of control algae consumption as a percentage of total consumption (consumption of control algae/ [consumption of grazed + control algae] $\times 100)$ for each species, using (A) live and (B) agar-based food containing nonpolar algal extracts. Values of $50 \%$ indicate equal consumption rates of grazed and control algae, and values $>50 \%$ indicate preference of control and $<50 \%$, preference for grazed algae. Black, treatment phase; white, recovery phase; asterisks indicate significant results from paired $t$-tests at $\alpha=0.05$ (note discontinuous ordinate). 
preferred (91\% of total consumption, Fig. 1A) over grazed conspecifics (paired $t$-test: $t_{4}=3.78, P=$ 0.019 ): The mean consumption $\pm \mathrm{SD}$ was $0.99 \pm$ $0.45 \mathrm{~g}$ and $-0.06 \pm 0.38 \mathrm{~g}$ for control and grazed algae, respectively. At the end of the recovery phase, preference of control algae over grazed conspecifics was still apparent (61\% of total consumption, Fig. 1A) but was much less than at the end of the treatment phase. Differences in consumption rates between recovered control and grazed individuals were not significant (paired $t$-test: $t_{4}=0.65, P=0.549$ ): $1.91 \pm$ $1.52 \mathrm{~g}$ and $1.08 \pm 1.41 \mathrm{~g}$ for control and grazed algae, respectively.

Nonpolar algal extracts: At the end of the treatment phase, extracts of control algae were significantly more consumed $(74 \%$ of total consumption, Fig. 1B) than extracts from grazed conspecifics (paired $t$-test: $\left.t_{4}=2.89, P=0.044\right): 22.2 \pm 8.0$ and $10.2 \pm$ 10.2 squares for control and grazed algae, respectively. After algae passed the recovery phase, amphipods hardly preferred control algae $55 \%$ of total consumption, Fig. 1B) over grazed conspecifics. This difference was not statistically significant (paired $t$-test: $\left.t_{4}=0.49, P=0.648\right)$ : consumption rates of $16.6 \pm 9.7$ and $14.2 \pm 9.2$ squares for control and grazed algae, respectively.

Hypnea pannose. Live algae: Feeding assays after the treatment phase revealed strong feeding preference of amphipods for control over grazed algae (91\% of total consumption, Fig. 1A). Control algae were significantly more consumed than grazed algae (paired $t$-test: $t_{4}=2.88, P=0.045$ ): $0.51 \pm$ $0.21 \mathrm{~g}$ and $0.002 \pm 0.21 \mathrm{~g}$, respectively. At the end of the recovery phase, amphipod feeding preference for control live algae was moderately reduced compared with that after the treatment phase but was still strong ( $82 \%$ of total consumption). Despite this strong preference, consumption rates between control and grazed algal specimens were not significantly different (paired $t$-test: $t_{4}=1.89, P=0.132$ ): $0.92 \pm$ $0.32 \mathrm{~g}$ and $0.27 \pm 0.49 \mathrm{~g}$, respectively.

Nonpolar algal extracts: Amphipods did not discriminate between extracts from control and grazed algae at the end of the treatment phase (Fig. 1B). Algal palatability was not significantly affected between control and grazed algae (paired $t$-test: $t_{4}=-0.23$, $P=0.827): 7.4 \pm 4.2$ and $8.2 \pm 5.0$ squares, respectively. Interestingly, amphipod feeding preference for extracts of control algae was strongly increased (69\% of total consumption) after the 14-day recovery period. As a nonsignificant trend, amphipod consumption of nonpolar extracts from control algae was higher than those of grazed algae (paired $t$-test: $\left.t_{4}=2.49, \quad P=0.067\right): 28.0 \pm 5.8$ and $16.2 \pm 13.2$ squares, respectively.

Cystoseira myrica. Live algae: At the end of the treatment phase, feeding preference for control over grazed algae was apparent (Fig. 1A), although feeding assays did not detect a significant difference (paired $t$-test: $t_{4}=2.16, P=0.098$ ) in consumption of control $(0.85 \pm 0.46 \mathrm{~g})$ and grazed algae $(0.26 \pm$ $0.14 \mathrm{~g})$. At the end of the recovery phase, amphipod preference for control individuals further increased (79\% of total consumption) over that of grazed algae, but feeding assays still did not reveal a significant difference (paired $t$-test: $t_{4}=2,17, P=0.096$ ) in consumption rates: $2,17 \pm 1.77 \mathrm{~g}$ and $0.39 \pm 0.31 \mathrm{~g}$ for control and grazed algae, respectively.

Nonpolar algal extracts: At the end of the treatment phase, control algae were significantly preferred by amphipods over grazed conspecifics (paired $t$-test: $\left.t_{4}=2.89, P=0.045\right): 9.0 \pm 6.2$ and $3.4 \pm 3.7$ squares, respectively. At the end of the recovery phase, feeding preference for control algae $(72 \%$ of total consumption, Fig. 1B) over grazed conspecifics continued to be high, but the difference between consumption rates was no longer statistically significant (paired $t$-test: $t_{4}=2.45, P=0.071$ ): $17.0 \pm 7.6$ and $8.4 \pm 7.2$ squares for control and grazed algal specimen, respectively.

\section{DISCUSSION}

Grazing by the amphipod Cymadusa filosa lowered algal palatability in all three species, relative to control algae. These repulsive effects were observed 1) both in live algae and agar-based food containing nonpolar algal extracts (Sargassum asperifolium, brown alga), 2) in nonpolar extracts alone (Cystoseira myrica, brown alga), or 3) solely in live algae (Hypnea pannosa, red alga), adding additional evidence that inducible anti-herbivore defenses are not taxonomically restricted to brown algae. Furthermore, deterrent effects disappeared within 14 days after grazing ceased, but the magnitude of this reduction in defenses varied among species.

All three algae studied in Kenya induced anti-herbivore defenses. This is surprising, because grazing pressure has been reported to be very intense in tropical ecosystems (e.g. coral reefs; Hay 1997). Because of a permanent exposure to an array of consumers, it could be inferred that macroalgae from these sites have more effective defenses (Bolser and Hay 1996), which suggests constitutive, rather than inductive, defense responses. However, our study indicates that this cannot be generally assumed, at least when the amphipod C. filosa is considered.

We detected after the treatment but not after the recovery phase a strong preference for control $S$. asperifolium pieces over grazed conspecifics, which was interpreted as an induction of anti-herbivore defense. An induction of defense was displayed by both live algae and agar-based food containing nonpolar algal extracts. The stronger feeding preference for control over grazed Sargassum individuals in feeding assays using live algae rather than the food containing nonpolar extracts suggests that a far more repellent trait has been induced in either polar compounds of $S$. asperifolium, in the morphology of this alga, or in both compared with nonpolar algal compounds. The 
induction of morphological anti-herbivore defenses has been rarely shown in macroalgae (Lewis et al. 1987). Because the current study did not assess changes in morphological thallus traits, the possibility of induced morphological defenses cannot be ruled out. Interestingly, amphipods hardly discriminated between live control and grazed S. asperifolium pieces within 14 days after the algae were released from grazing pressure. Possibly $S$. asperifolium induces a blend of polar and nonpolar chemical compounds to deter grazing amphipods. This is supported by similar preference levels of controls versus grazed specimens in live algae (61\% of total consumption) and extracts (55\% of total consumption) after grazing had ceased, suggesting a decline of chemical defensive traits in both food types.

Control pieces of $H$. pannosa were consumed more than grazed conspecifics in feeding assays using live algae but not when nonpolar algal extracts were compared. This result suggests that morphological anti-herbivore defenses were induced or that the production of polar chemical substances was initiated as a result of amphipod exposure. Besides Weidner et al. (2004), this is the only report on induced chemical defenses in red macroalgae. Interestingly, the pattern of induction and reduction of anti-herbivore defenses in $H$. pannosa was similar to that of Lobophora variegata in the investigation of Weidner et al. (2004). Induced resistance to amphipod grazing in nonpolar extracts, but not in live algae of the third species, C. myrica, seems spurious. However, it can be speculated that the polar extracts of this alga contain palatable substances that are more attractive for the amphipods used in this study than nonpolar substances are repellent. A similar result has been reported for the brown alga $L$. variegata from Brazil (Weidner et al. 2004), suggesting that grazing attracting and deterring substances occur at least occasionally in macroalgal tissues at the same time.

Lack of significant grazing effects after the recovery phase on algal palatability in all three species tested suggest a consistent pattern of reduced (live algae: S. asperifolium, H. pannosa; artificial food: S. asperifolium, C. myrica) or unchanged (live algae: C. myrica; artificial food: $H$. pannosa) levels of anti-herbivore defenses after amphipods were removed. In particular, feeding preferences for control algae of $S$. asperifolium over grazed conspecifics were strongly lowered within the 14-day grazer-free period, indicating rapid attenuation of repellent traits. The speed of reduced deterrent action of induced defenses in S. asperifolium corresponds well with the relaxation times reported for clipping-induced defenses in Fucus vesiculosus (Hemmi et al. 2004). Although Hemmi et al. (2004) speculate that the short-term repulsive response of $F$. vesiculosus could be regarded as a side effect of wound-healing processes, alternative explanations are also possible. For instance, macroalgae could reduce metabolic costs by producing defenses "on demand" or short-term production of anti-herbivore defenses could lower the risk of autotoxicity (Agrawal and Karban 1999). However, feeding preference for control algae of the remaining two algal species in this study continued to be high (i.e. $>70 \%$ of total consumption) or was even increased during the grazer-free period after the treatment phase (e.g. H. pannosa extracts), suggesting a time lag in the inductive defense response. Different preference levels of control versus grazed algae among the three species at the end of the recovery phase indicate species-specific rates in reducing anti-herbivore defenses in macroalgae after grazing had ceased, which has not been shown previously.

In conclusion, we were able to show that two brown and one red macroalgae off the Kenyan coast induced anti-herbivore defenses in response to grazing by the amphipod C. filosa. Furthermore, we demonstrated that inducible grazer-deterrent traits exist in nonpolar algal extracts. The speed of reduction of repulsive traits was species specific, being strongest in the brown alga $S$. asperifolium. Our results suggest that inducible defenses can also be an effective mechanism to affect the abundance and distribution of various tropical seaweed species.

We thank the staff of the Kenya Marine and Fisheries Research Institute for logistic support and cooperation. The comments of two anonymous reviewers greatly improved the quality of the manuscript. This study was part of the international research and student training program GAME (Global Approach by Modular Experiments) funded by the Foundation Mercator to M. W.

Adler, F. R. \& Karban, R. 1994. Defended fortresses or moving targets-another model of inducible defenses inspired by military metaphors. Am. Nat. 144:813-32.

Agrawal, A. 1998. Induced response to herbivory and increased plant performance. Science 279:1201-2.

Agrawal, A. A. \& Karban, R. 1999. Why induced defenses may be favored over constitutive strategies in plants. In Tollrian, R. \& Harvell, C. [Eds.] The Ecology and Evolution of Inducible Defenses. Princeton University Press, Princeton, NJ, pp. 45-61.

Baldwin, I. T. 1998. Jasmonate induced responses are costly but benefit plants under attack in native populations. Proc. Natl. Acad. Sci. USA 95:8113-8.

Bolser, R. \& Hay, M. E. 1996. Are tropical plants better defended? Palatability and defenses of temperate vs tropical seaweeds. Ecology 77:2269-86.

Brawley, S. 1992. Mesoherbivores. In John, S., Hawkins, S. \& Price, J. [Eds.] Plant-Animal Interactions in the Marine Benthos. Clarendon Press, Oxford, pp. 235-63.

Cronin, G. 2001. Resource allocation in seaweeds and marine invertebrates: chemical defense patterns in relation to defense theories. In McClintock, J. \& Baker, B. [Eds.] Marine Chemical Ecology. CRC Press, Boca Raton, FL, pp. 325-53.

Cronin, G. \& Hay, M. E. 1996. Induction of seaweed chemical defenses by amphipod grazing. Ecology 77:2287-301.

Deal, M. S., Hay, M. E., Wilson, D. \& Fenical, W. 2003. Galactolipids rather than phlorotannins as herbivore deterrents in the brown seaweed Fucus vesiculosus. Oecologia 136:107-14.

Duffy, J. E. \& Hay, M. E. 1994. Herbivore resistance to seaweed chemical defense: the roles of mobility and predation risk. Ecology 75:1304-19.

Hammerström, K., Dethier, M. N. \& Duggins, D. O. 1998. Rapid phlorotannin induction and relaxation in five Washington kelps. Mar. Ecol. Prog. Ser. 165:293-305.

Harvell, C. D. \& Tollrian, R. 1999. Why inducible defenses? In Tollrian, R. \& Harvell, C. D. [Eds.] The Ecology and Evolution of 
Inducible Defenses. Princeton University Press, Chichester, UK, pp. 3-9.

Hay, M. E. 1985. Spatial patterns of herbivore impact and their importance in maintaining algal species richness. Proceedings of the 5th International Coral Reef Congress, Tahiti, 4:29-34.

Hay, M. E. 1996. Marine chemical ecology: what is known and what is next. J. Exp. Mar. Biol. Ecol. 200:103-34.

Hay, M. E. 1997. The ecology and evolution of seaweed-herbivore interactions on coral reefs. Coral Reefs 16(suppl):S67-76.

Hay, M. E. \& Fenical, W. 1988. Marine plant-herbivore interactions: the ecology of chemical defense. Annu. Rev. Ecol. Syst. 19:111-45.

Hemmi, A., Honkanen, T. \& Jormalainen, V. 2004. Inducible resistance to herbivory in Fucus vesiculosus-duration, spreading and variation with nutrient availability. Mar. Ecol. Prog. Ser. 273:109-20.

Jormalainen, V., Jonkanen, T. \& Heikkilä, N. 2001. Feeding preferences and performance of a marine isopod on seaweed hosts: cost of habitat specialization. Mar. Ecol. Prog. Ser. 220:219-30.

Karban, R. 1993. Costs and benefits of induced resistance and plant density for a native shrub, Gossypium thurberi. Ecology 74:9-19.

Karban, R., Agrawal, A. A., Thaler, J. S. \& Adler, L. S. 1999. Induced plant responses and information content about risk of herbivory. Trends Ecol. Evol. 14:443-7.
Kubanek, J., Lester, S E., Fenical, W. \& Hay, M. E. 2004. Ambiguous role of phlorotannins as chemical defenses in the brown alga Fucus vesiculosus. Mar. Ecol. Prog. Ser. 277:79-93.

Lewis, S. M., Norris, J. N. \& Searles, R. B. 1987. The regulation of morphological plasticity in tropical reef algae by herbivory. Ecology 68:636-41.

Lubchenco, J. \& Gaines, S. D. 1981. A unified approach to the marine, plant herbivore interactions. I. Populations and communities. Rev. Eco. Syst. 12:405-37.

Pavia, H. \& Toth, G. B. 2000. Inducible chemical resistance to herbivory in the brown seaweed Ascophyllum nodosum. Ecology $81: 3212-25$.

Rohde, S., Molis, M. \& Wahl, M. 2004. Regulation of anti-herbivore defence by Fucus vesiculosus in response to various cues. J. Ecol., 92:1011-18.

Sotka, E., Taylor, R. B. \& Hay, M. E. 2002. Tissue-specific induction of resistance to herbivores in a brown seaweed: the importance of direct grazing versus waterborne signals from grazed neighbours. J. Exp. Mar. Biol. Ecol. 277:1-12.

Uku, J. \& Björk, M. 2001. The distribution of epiphytic algae on three Kenyan seagrass species. S. Afr. J. Bot. 67:475-82.

Weidner, K., Lages, B. G., da Gama, B. A. P., Molis, M., Wahl, M. \& Pereira, R. C. 2004. Effects of mesograzers and nutrient levels on the induction of defenses in several Brazilian macroalgae. Mar. Ecol. Prog. Ser., 283:113-25. 